\title{
Is ABO-Compatible but Non-Identical Intestinal Transplant Comparable to ABO-Identical Transplant? An Analysis of the UNOS Registry
}

\author{
Junchao Cai ${ }^{1 *}$, Xin Qing ${ }^{2}$, Guosheng Wu ${ }^{3}$, Matthew Everly ${ }^{1}$, Elaine Cheng ${ }^{1,4}$, Paul Terasaki ${ }^{1}$ \\ ${ }^{1}$ Terasaki Foundation Laboratory, Los Angeles, CA, United States \\ ${ }^{2}$ Department of Pathology, Harbor-UCLA Medical Center, Torrance, CA, United States \\ ${ }^{3}$ Xijing Hospital of Digestive Diseases, the Fourth Military Medical University, Xi'an, China \\ ${ }^{4}$ Department of Surgery, UCLA Medical School, Los Angeles, CA, United States
}

Received: August 18, 2015; Accepted: September 28, 2015; Published: October 31, 2015

*Corresponding author: Junchao Cai, Terasaki Foundation Laboratory, 11570 W Olympic Blvd. Los Angeles, CA 90064, USA, Tel: +310-479-6101;

E-mail: cai@terasakilab.org

\begin{abstract}
Absract
ABO-compatible intestinal transplants have been more frequently performed in the US in recent years (from $4 \%$ to $16 \%$ ). However, they have not been clearly shown to have comparable short- and long-term graft outcome compared to $\mathrm{ABO}$-identical transplants.

The US national registry database was analyzed to show the current status of $\mathrm{ABO}$-compatible intestinal transplantation and to determine its effect on acute rejection and long-term graft survival.

Blood type $\mathrm{A}, \mathrm{B}$, and $\mathrm{AB}$ patients received $11 \%, 26 \%$, and $62 \%$ of ABO-compatible intestinal transplants, respectively. ABO-compatible transplant recipients experienced a higher rate of acute rejection than ABO-identical patients ( $77 \%$ vs. $64 \%, p<0.0001)$. In addition, they had a significantly lower 10 -year graft survival rate than $\mathrm{ABO}$-identical transplant recipients $(27 \%$ vs. $35 \%, p=0.020)$. Acute rejection was the cause of graft failure in $42 \%$ of ABO-compatible and $25 \%$ of ABOidentical patients who lost intestinal transplants $(p=0.041)$.

Since ABO-compatible transplants were associated with high rates of acute rejection and graft failure, intense induction/maintenance immunosuppressive therapies are recommended for $\mathrm{ABO}$-compatible transplant recipients. In addition, packed red blood cells of donor type and plasma of recipient type, if needed, should be considered as a safer transfusion strategy for $\mathrm{ABO}$-compatible transplant patients to avoid intensification of allograft injury by GVH immunity.
\end{abstract}

Keywords: Small bowel transplantation; $\mathrm{ABO}$ compatibility; Rejection; Graft survival

\section{Abbreviations}

GVH: Graft-Versus-Host

\section{Introduction}

ABO-compatible but non-identical transplants have been performed in all organ types for decades. It is controversial whether ABO-compatible transplants have comparable outcomes compared to identical transplants. Some studies have shown ABO-compatible and identical transplants have similar graft survival in the heart [1,2], lung [3,4], and liver [5] transplants. However, careful investigation of these studies demonstrates that ABO-compatible transplants have lower graft survival than identical transplants in some of these studies, though the differences do not reach statistical significance. Koukoutisis [6] and Bjoro [7] reported that ABO-compatible liver transplant recipients actually have significantly lower graft and patient survival than $\mathrm{ABO}$-identical transplant patients.

Compared to other organ transplantation, intestinal transplantation remains the least frequently performed transplantation. There are more than 40 US centers performing intestinal transplants and case numbers in recent years were only around 100 per year in the US, with most centers performing fewer than 10 transplants per year [8]. With limited intestinal transplant cases, it is very difficult or it may take a long time for a single center to provide convincing evidence to show whether ABO-compatible and identical transplants have comparable graft outcome, especially long-term outcome. Our recent analysis demonstrated that during $1990-2013,9.7 \%$ of US intestinal recipients received transplants from $\mathrm{ABO}$-compatible donors. More importantly, we found there was a very significant increasing trend of $\mathrm{ABO}$-compatible intestinal transplants in recent years (from $4 \%$ to $16 \%$ ). These findings make it urgent to know whether it is safe to perform ABO-compatible intestinal transplantation and what we should do to minimize the potential risk if the ABO-compatible transplant is associated with graft failure. By analyzing US national registry data, we show the current status of ABO-compatible intestinal transplantation in the US and its detrimental effects on short- and long-term intestinal allograft outcomes. We also discuss the potential mechanisms of graft-versus-host reaction-induced graft injury and corresponding strategies.

\section{Materials and Methods}

\section{Study population}

Between 1/1/1990 and 6/27/2013, a total of 2,287 US intestinal transplants were reported to the Organ Procurement 
and Transplantation Network and were included in this study Among them, 2,061 (90.3\%) patients received ABO-identical transplants and 222 patients $(9.7 \%)$ received $\mathrm{ABO}$-compatible transplants. Four patients who received $\mathrm{ABO}$ incompatible intestinal transplants were excluded from this study. Patient demographics of ABO-compatible and ABO-identical transplant recipients are summarized in Table 1.

\section{Statistical Analysis}

All statistical analyses were performed using STATA version

Table 1: Patient demographics.

\begin{tabular}{|c|c|c|c|}
\hline Variables & ABO identical & $\begin{array}{l}\text { ABO } \\
\text { compatible }\end{array}$ & p-value \\
\hline Case No. & 2061 & 222 & \\
\hline patient gender (female) & $47.99 \%$ & $51.35 \%$ & 0.3400 \\
\hline donor gender (female) & $40.27 \%$ & $40.09 \%$ & 0.9580 \\
\hline patient age & $20.02 \pm 0.46$ & $19.15 \pm 1.40$ & 0.5506 \\
\hline donor age & $11.58 \pm 0.29$ & $9.8 \pm 0.77$ & 0.0530 \\
\hline $\begin{array}{l}\text { patient race (white/ } \\
\text { nonwhite) }\end{array}$ & $70.31 \%$ & $60.36 \%$ & 0.0000 \\
\hline donor race (white) & $63.03 \%$ & $55.41 \%$ & 0.5980 \\
\hline HLA mismatches & $4.64 \pm 0.03$ & $4.61 \pm 0.08$ & 0.6874 \\
\hline A locus & & & 0.0980 \\
\hline No mismatch & $6.46 \%$ & $10.53 \%$ & \\
\hline 1 mismatch & $42.32 \%$ & $38.95 \%$ & \\
\hline 2 mismatches & $51.22 \%$ & $50.53 \%$ & \\
\hline B locus & & & 0.5360 \\
\hline No mismatch & $2.01 \%$ & $1.05 \%$ & \\
\hline 1 mismatch & $26.10 \%$ & $24.21 \%$ & \\
\hline 2 mismatches & $71.89 \%$ & $74.74 \%$ & \\
\hline DR locus & & & 0.8100 \\
\hline No mismatch & $5.25 \%$ & $6.2 \%$ & \\
\hline 1 mismatch & $40.33 \%$ & $40.53 \%$ & \\
\hline 2 mismatches & $54.43 \%$ & $53.16 \%$ & \\
\hline patient CMV IgG+ & $35.19 \%$ & $34.27 \%$ & 0.0090 \\
\hline patient CMV IgM+ & $3.23 \%$ & $2.16 \%$ & 0.4900 \\
\hline donor anti CMV serology+ & $45.51 \%$ & $44.55 \%$ & 0.0730 \\
\hline $\begin{array}{l}\text { patient HBV surface antigen } \\
+\%\end{array}$ & $1.58 \%$ & $2.48 \%$ & 0.0020 \\
\hline patient HCV serostatus $+\%$ & $1.52 \%$ & $0.94 \%$ & 0.0000 \\
\hline Patient EBV serostatus (+ \%) & $55.87 \%$ & $57.63 \%$ & 0.6555 \\
\hline Donor anti-EBV IgG (+ \%) & $73.88 \%$ & $78.99 \%$ & 0.2320 \\
\hline Donor anti-EBV IgM (+ \%) & $2.24 \%$ & $0.92 \%$ & 0.3650 \\
\hline $\begin{array}{l}\text { Donor cause of death (head } \\
\text { trauma \%) }\end{array}$ & $58.14 \%$ & $56.40 \%$ & 0.6250 \\
\hline patient weight (kg) & $39.23 \pm 0.66$ & $35.99 \pm 1.89$ & 0.1231 \\
\hline $\begin{array}{l}\text { Donor type (deceased donor } \\
\%)\end{array}$ & $98.59 \%$ & $95.05 \%$ & 0.0000 \\
\hline Total ischemic time (hr) & $7.91 \pm 0.06$ & $7.62 \pm 0.25$ & 0.1419 \\
\hline
\end{tabular}

Citation: Cai J, Qing X, Wu G, Everly M, Cheng E, et al. (2015) Is ABO-Compatible but Non-Identical Intestinal Transplant Comparable to ABO-Identical Transplant? An Analysis of the UNOS Registry. SOJ Immunol 3(5): 1-9. DOI: DOI: http://dx.doi.org/10.15226/2372$0948 / 3 / 5 / 00139$

\begin{tabular}{|c|c|c|c|}
\hline primary tx \% & $90.64 \%$ & $90.54 \%$ & 0.9630 \\
\hline Multiorgan tx & & & 0.1370 \\
\hline Intestine only & $38.38 \%$ & $45.05 \%$ & \\
\hline multivisceral tx with liver & $54.63 \%$ & $49.55 \%$ & \\
\hline multivisceral tx without liver & $6.00 \%$ & $5.41 \%$ & \\
\hline Patient primary diagnosis & & & 0.3010 \\
\hline Short gut syndrome & $75.77 \%$ & $81.25 \%$ & \\
\hline functional bowel problem & $17.44 \%$ & $13.94 \%$ & \\
\hline retransplant & $5.46 \%$ & $3.37 \%$ & \\
\hline others & $1.32 \%$ & $1.44 \%$ & \\
\hline patient on life support at tx & $14.58 \%$ & $15.98 \%$ & 0.5820 \\
\hline $\begin{array}{l}\text { Patient liver dysfunction at } \\
\text { tx (+ \%) }\end{array}$ & $61.68 \%$ & $74.42 \%$ & 0.0190 \\
\hline $\begin{array}{l}\text { Induction therapy recipient } \\
(\%)\end{array}$ & $68.27 \%$ & $60.81 \%$ & 0.0240 \\
\hline $\begin{array}{l}\text { No. of maintenance of } \\
\text { immunosuppression }\end{array}$ & $2.06 \pm 0.84$ & $2.18 \pm 0.88$ & 0.0000 \\
\hline 0 & $4.37 \%$ & $6.76 \%$ & \\
\hline 1 & $15.82 \%$ & $7.66 \%$ & \\
\hline 2 & $53.13 \%$ & $49 \%$ & \\
\hline 3 & $23.48 \%$ & $33.78 \%$ & \\
\hline 4 & $2.91 \%$ & $2.70 \%$ & \\
\hline 5 & $0.29 \%$ & $0 \%$ & \\
\hline
\end{tabular}

13 (StataCorp LP, College Station, TX) with all available updates as of January 2015. The difference in the distribution of categorical variables between groups was investigated using the chi-square test. Unpaired-test or one-way analysis of variance was used for numerical variables. Graft survival rates of transplant recipients were estimated using Kaplan-Meier methods, with significance determined by log-rank test.

To determine whether ABO-compatible but non-identical transplantation is an independent risk factor associated with acute rejection, univariate logistic regression analysis were used to screen all potential risk factors, and multivariate logistic regression analysis were used to calculate odds ratios for the associations between acute rejection occurrence and ABOcompatible transplantation while adjusting for other risk factors of acute rejection. Variables in the final multivariate logistic regression model included $\mathrm{ABO}$-compatible transplants $0=$ identical, $1=$ compatible $)$, patient and donor race $(0=$ white, 1 = non-white), patient age, total ischemic time (hours), multiorgan transplantation $(0=$ intestine alone, $1=$ multivisceral transplantation with liver, $2=$ multivisceral transplantation without liver), induction immunosuppression ( $0=$ No, $1=$ Yes $)$, and number of maintenance of immunosuppression. ABOcompatible transplantation had an odds ratio of 1.85 with a p-value of 0.001 .

To establish multivariate Cox models, the registry data were first explored using univariate analyses to screen for potential predictors of graft loss. The log-rank test was used for categorical variables, whereas univariate Cox proportional hazard 
regression was used for continuous variables. The variable with a p-value of less than or equal to 0.2 was included as a potential predictor of graft failure in a stepwise Cox model. The limit for stepwise backward and forward elimination was $p<0.1$. The variables with more than $10 \%$ missing observations were excluded from multivariate Cox analysis (Table 2). The final Cox model included donor and recipient compatibility of ABO blood group (compatible), recipient age, non-white donor, donor cause of death (non-head trauma), regraft, number of maintenance immunosuppressants, induction immunosuppression, transplant year (Table 3). In the final multivariate Cox analyses, data were reported as a hazard ratio (relative risk of graft failure) with a $95 \%$ confidence interval. Two-sided p-value less than 0.05 were considered significant.

\section{Results}

ABO-compatible transplant recipients include blood group

Table 2: Univariate analysis of potential risk factors for intestinal graft failure.

\begin{tabular}{|c|c|c|c|c|}
\hline Variables & $\begin{array}{l}\text { Hazard } \\
\text { ratio }\end{array}$ & p-value & $\begin{array}{l}\text { Observation } \\
\text { number }\end{array}$ & $\begin{array}{l}\text { Missing } \\
\text { observation } \\
\%\end{array}$ \\
\hline $\begin{array}{l}\text { donor anti-EBV } \\
\text { IgM + }\end{array}$ & 1.5593 & 0.1660 & 874 & $61.72 \%$ \\
\hline $\begin{array}{l}\text { patient HCV } \\
\text { serostatus + }\end{array}$ & 1.4568 & 0.1150 & 1437 & $37.06 \%$ \\
\hline $\begin{array}{l}\text { patient HBV surface } \\
\text { antigen }+\end{array}$ & 1.4476 & 0.1030 & 1508 & $33.95 \%$ \\
\hline regraft & 1.3565 & 0.0010 & 2301 & No \\
\hline $\begin{array}{l}\text { ABO compatible } \\
\text { transplant }\end{array}$ & 1.2439 & 0.0200 & 2283 & No \\
\hline $\begin{array}{l}\text { donor race (non- } \\
\text { white) }\end{array}$ & 1.2372 & 0.0000 & 2303 & No \\
\hline patient CMV IgG+ & 1.1914 & 0.0120 & 1659 & $27.33 \%$ \\
\hline $\begin{array}{l}\text { induction therapy } \\
\text { recipient }\end{array}$ & 1.1531 & 0.0210 & 2303 & No \\
\hline $\begin{array}{l}\text { donor cause of death } \\
\text { (non head trauma) }\end{array}$ & 1.1413 & 0.0220 & 2255 & $1.23 \%$ \\
\hline donor age & 1.0087 & 0.0000 & 2300 & No \\
\hline patient age & 1.0045 & 0.0010 & 2302 & No \\
\hline patient weight (kg) & 1.0029 & 0.0030 & 2187 & $4.20 \%$ \\
\hline transplant year & 0.9692 & 0.0000 & 2302 & No \\
\hline multiorgan tx & 0.8942 & 0.0190 & 2303 & No \\
\hline $\begin{array}{l}\text { No. of } \\
\text { maintenance of } \\
\text { immunosuppression }\end{array}$ & 0.8919 & 0.0010 & 2303 & No \\
\hline $\begin{array}{l}\text { patient liver } \\
\text { dysfunction at tx }\end{array}$ & 0.8906 & 0.1160 & 1202 & $47.35 \%$ \\
\hline $\begin{array}{l}\text { total ischemic time } \\
\text { (hr) }\end{array}$ & 1.0161 & 0.2150 & 2023 & $11.39 \%$ \\
\hline $\begin{array}{l}\text { donor anti CMV } \\
\text { serology+ }\end{array}$ & 1.0690 & 0.2440 & 2241 & $1.84 \%$ \\
\hline $\begin{array}{l}\text { patient on life } \\
\text { support at tx }\end{array}$ & 1.0952 & 0.2610 & 2280 & $0.13 \%$ \\
\hline donor anti-EBV IgG + & 1.1472 & 0.2690 & 928 & $59.35 \%$ \\
\hline
\end{tabular}

\begin{tabular}{|l|l|l|l|l|}
\hline $\begin{array}{l}\text { patient EBV } \\
\text { serostatus + }\end{array}$ & 0.9319 & 0.2870 & 1782 & $21.94 \%$ \\
\hline $\begin{array}{l}\text { donot type (living } \\
\text { donor) }\end{array}$ & 1.2285 & 0.3090 & 2302 & No \\
\hline HLA mismatches & 1.0139 & 0.6120 & 2037 & $10.78 \%$ \\
\hline DR locus mismatch & 1.0196 & 0.6970 & 2037 & $10.78 \%$ \\
\hline A locus mismatch & 1.0188 & 0.6990 & 2050 & $10.21 \%$ \\
\hline patient CMV IgM+ & 1.0638 & 0.7700 & 1542 & $32.46 \%$ \\
\hline $\begin{array}{l}\text { patient primary } \\
\text { diagnosis (FBP) }\end{array}$ & 1.0173 & 0.8270 & 1902 & $16.69 \%$ \\
\hline B locus mismatch & 1.0108 & 0.8610 & 2050 & $10.21 \%$ \\
\hline $\begin{array}{l}\text { patient race (non- } \\
\text { white) }\end{array}$ & 1.0079 & 0.8990 & 2303 & No \\
\hline $\begin{array}{l}\text { patient gender } \\
\text { (female) }\end{array}$ & 0.9952 & 0.9310 & 2303 & No \\
\hline $\begin{array}{l}\text { donor gender } \\
\text { (female) }\end{array}$ & 0.9956 & 0.9390 & 2302 & No \\
\hline
\end{tabular}

Table 3: Independent predictors of intestinal graft failure.

\begin{tabular}{|l|l|l|}
\hline Variables & Hazard ratio & $\mathbf{p}$ \\
\hline ABO compatible transplantation & 1.417 & 0.000 \\
\hline recipient age & 1.006 & 0.000 \\
\hline nonwhite donor & 1.314 & 0.000 \\
\hline non-head trauma donor & 1.138 & 0.026 \\
\hline regraft & 1.427 & 0.000 \\
\hline No. of maintenance immunosuppressants & 0.871 & 0.000 \\
\hline induction immmunosuppression & 1.139 & 0.049 \\
\hline transplant year & 0.959 & 0.000 \\
\hline
\end{tabular}

$A$ and $\mathrm{B}$ patients who received transplants from $\mathrm{O}$ donors and blood group $\mathrm{AB}$ patients who received transplants from $\mathrm{A}, \mathrm{B}$, or 0 donors. Figure $1 \mathrm{~A}$ shows the annual trend of $\mathrm{ABO}$-compatible intestinal transplantation in the US from Jan 1990 to Jun 20013. Linear regression analysis suggests a significant trend of an increase in the annual number of $\mathrm{ABO}$-compatible transplants ( $r 2=0.32, p=0.004$ ). This increasing trend is more obvious in recent years (from 4\% in 2003 to $16 \%$ in 2013). Among all ABOcompatible transplant recipients, $11 \%$ of blood group A and $26 \%$ of blood group B recipients received transplants from $\mathrm{ABO}$ group 0 donors, while $62 \%$ of group $\mathrm{AB}$ recipients received transplants from compatible donors of $A, B$, or $O$ blood types (Figure 1B).

A significantly higher percentage of ABO-compatible intestinal transplant recipients experienced acute rejection than ABO-identical transplant recipients (Table $4,77 \%$ vs. $64 \%$, $p<0.0001$ ). This comparison is based on the data collected before discharge since the reporting rates of acute rejection at 6 months and 1-year post-transplant were low (47-63\%). The association between occurrence of acute rejection and ABOcompatible transplantation was further verified in univariate and multivariate logistic regression analyses (see Materials and Methods for a detailed description). There is no difference between groups in the total number of rejection episodes each patient experienced $(p=0.7777)$. 
Figure 1A.

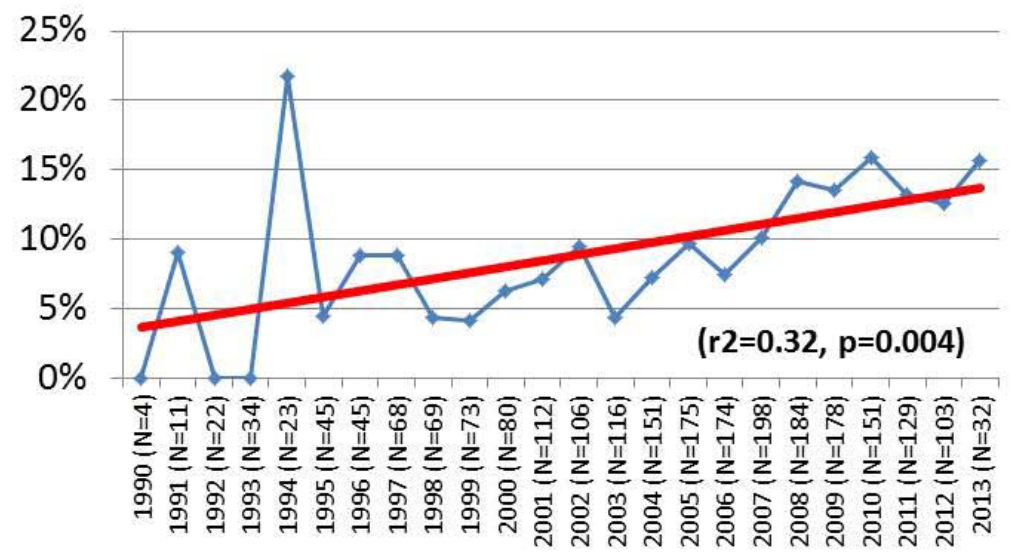

Figure 1B.

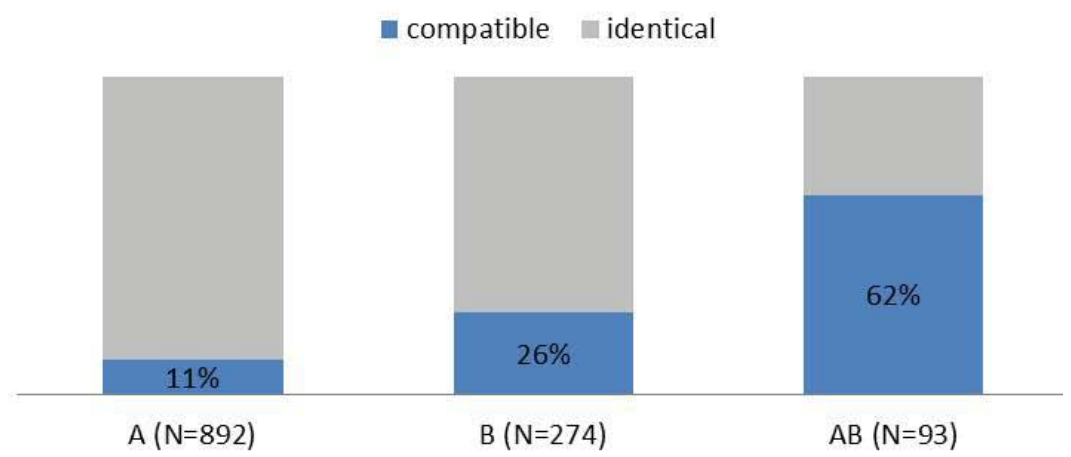

Figure 1: 1A: Increasing trend of ABO-compatible intestinal transplantation in the US; 1B) Percentages of ABO-compatible intestinal transplants by patient blood type

Table 4: Comparison of early rejection episode between groups.

\begin{tabular}{|c|c|c|}
\hline Rejection before discharge & Identical (N = 2061) & Compatible (N = 222) \\
\hline Acute rejection & & 0.0000 \\
\hline No & $742(36.00 \%)$ & $51(22.97 \%)$ \\
\hline Yes & $1319(64.00 \%)$ & $171(77.03 \%)$ \\
\hline Acute rejection episodes & $297(22.52 \%)$ & $42(24.56 \%)$ \\
\hline 1 & $21(1.59 \%)$ & $2(1.17 \%)$ \\
\hline 2 & $1001(75.89 \%)$ & $127(74.27 \%)$ \\
\hline
\end{tabular}

ABO-compatible transplant recipients had a significantly lower 10-year graft survival rate than $\mathrm{ABO}$-identical transplant recipients (Figure 2A). A more significant graft survival difference was observed in the intestine-alone transplantation which occurred within the 1st year post-transplant (Figure 2B). Transplantation of intestine with liver seemed to reduce the significance of the graft survival difference between $\mathrm{ABO}$ - compatible and identical transplants (Figure 2C). As described in the materials and methods section, after adjustment of all influencing variables, multivariate Cox analysis confirmed the association between $\mathrm{ABO}$-compatible transplantation and graft failure, with a hazard ratio of $1.42(p<0.001)$.

A total of 1,150 ABO-identical and 129 ABO-compatible 

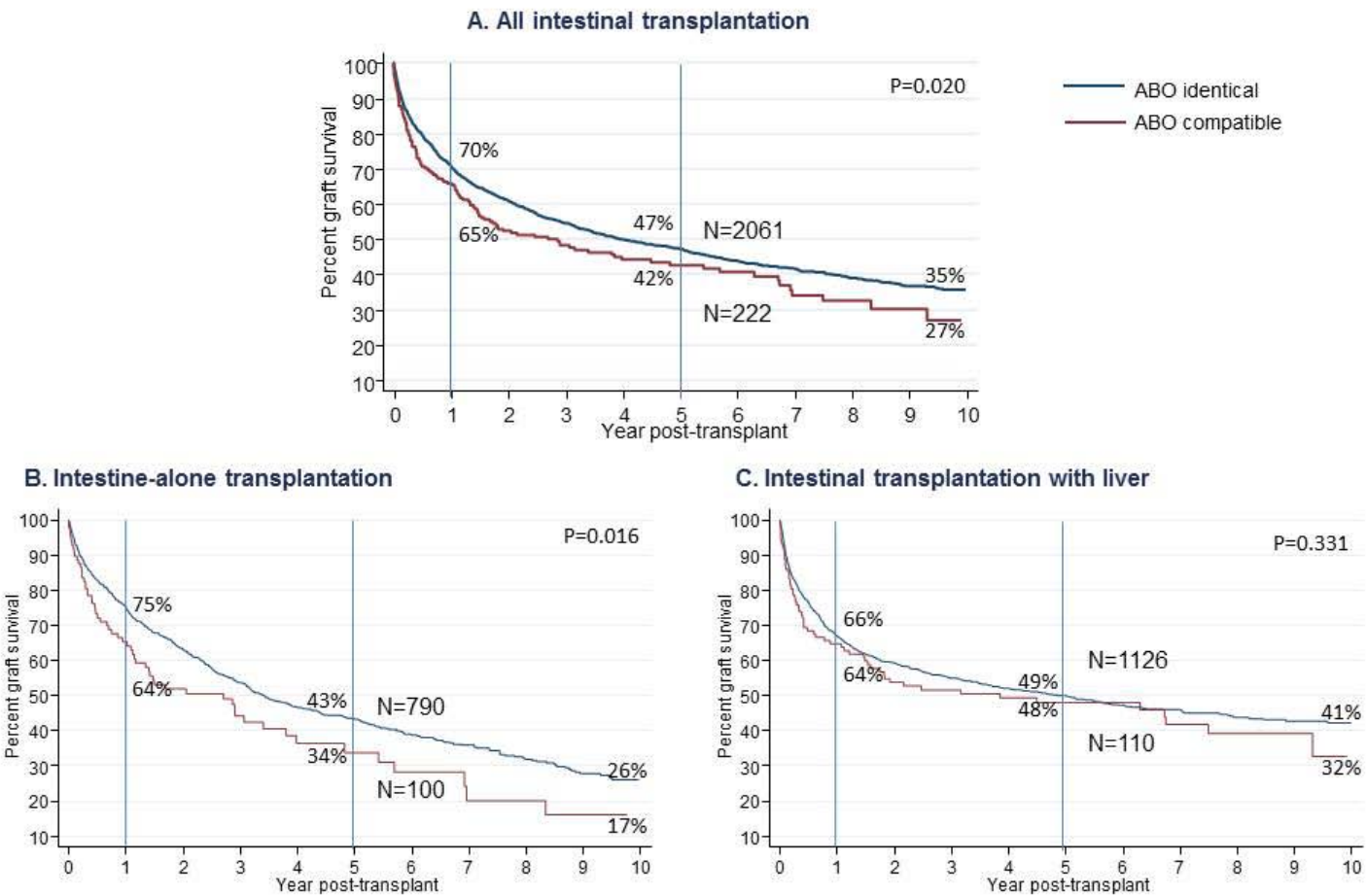

Figure 2: Ten-year graft survival of ABO-compatible and identical intestinal transplants. A. All intestinal transplants were included. B. Intestine-alone transplantation. C. Intestinal transplantation with liver.

transplant recipients lost allografts post-transplant. Causes of graft failure were reported to the registry for 525 (45.65\%) ABOidentical and 63 (48.84\%) compatible transplant recipients. Figure 3 shows that immunological causes (acute and chronic rejection) accounted for $52.5 \%$ and $54.0 \%$ of graft loss in ABO-identical and compatible transplantation, respectively. Interestingly, acute rejection alone accounted for $41 \%$ of all graft loss in ABOcompatible transplant recipients, which was significantly higher than that in ABO-identical transplant patients $(25 \%, p=0.041)$.

\section{Discussion}

In this study, very surprisingly, we found $\mathrm{ABO}$-compatible intestinal transplant recipients had a significantly higher chance of experiencing acute rejection than ABO-identical transplant recipients. More importantly, these patients also had a significantly lower rate of long-term graft survival. Analysis of the causes of graft failure indicates that acute rejection accounted for $41 \%$ of graft loss in $\mathrm{ABO}$-compatible transplantation, which is significantly higher than that in ABO-identical transplantation (25\%).

The major concern for ABO-compatible but non-identical transplantation is the potential risk of GVH antibodies against mismatched recipient ABO antigens. GVH antibodies might be obtained from plasma transfusions of donor type or from passive transfer of donor-derived antibodies [9-11]. It has also been proven that GVH antibodies can be produced by viable graftderived lymphocytes from lymphoid tissues of transplants [1013]. Bakr, et al. [14] reported that in ABO-compatible kidney transplantation, $\mathrm{GVH}$ antibodies causes hemolysis at the frequency of $60 \%$. Possibly due to the fact that kidney transplant contains fewer GVH antibodies and GVH antibody-producing cells, GVH antibody-induced hemolytic anemia was mild and does not cause serious consequences in kidney transplantation. In liver transplantation, with presumably more GVH antibodies or GVH antibody-producing cells, Koukoutisis [6] and Bjoro [7] reported that ABO-compatible transplant recipients have significantly lower graft and patient survival compared to ABO-identical transplant patients. The intestine possesses the largest mass of lymphoid tissue of any solid organ in the human body [15]. Not surprisingly, therefore, intestinal transplantation is reported to have a higher rate of GVH disease (GVHD, 5.6\%-9.1\%) [16-18] than a transplant of any other organ type, including liver (1$2 \%)[19,20]$. Since GVHD in transplant recipients is associated with a very high mortality rate (up to 85\%) [18] and intestinal transplant recipients have a high rate of GVHD, this may explain why ABO-compatible transplants have a lower graft survival than identical transplants.

Graft loss and patient death in intestinal transplant recipients with GVHD have been reported to be associated with the infection since GVH reactions may damage host lymphoid tissues and produce profound immunosuppression $[18,21]$. However, in this study, the percentage of graft loss due to infection is only slightly higher incompatible transplants than identical transplants (14.3\% vs. $10.7 \%)$, while graft loss resulting from acute rejection is much higher incompatible transplants than in identical transplants $(41.3 \%$ vs. $25.3 \%)$. These data imply that there might be a potential association between GVH reactions and acute rejection. 


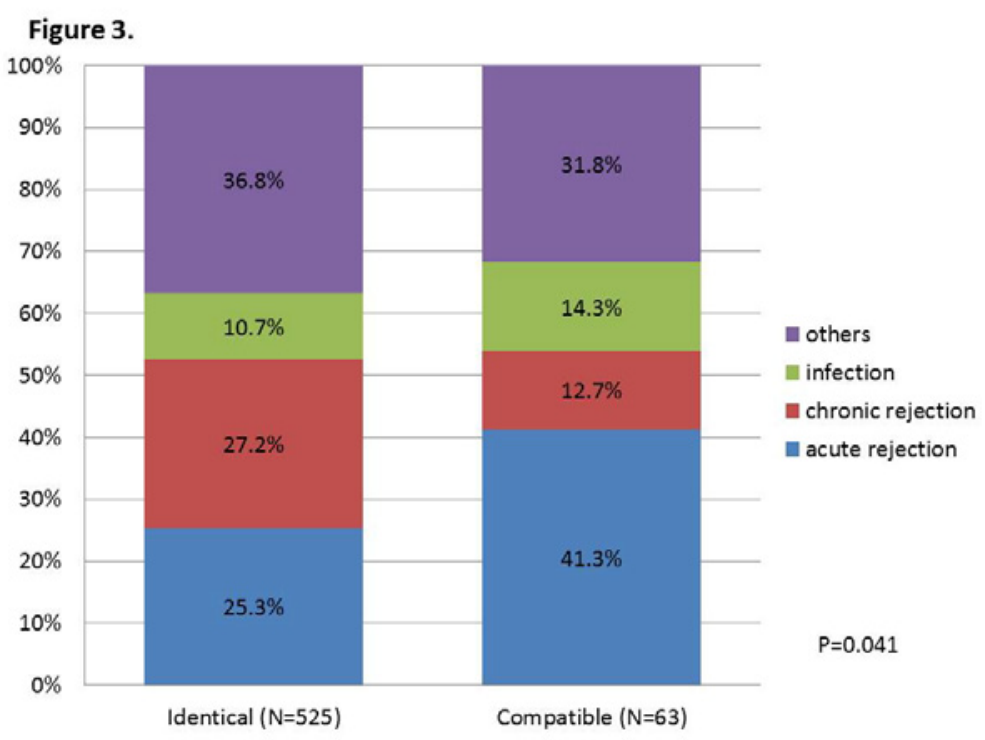

Figure 3: Causes of graft failure in ABO identical and compatible transplant recipients.
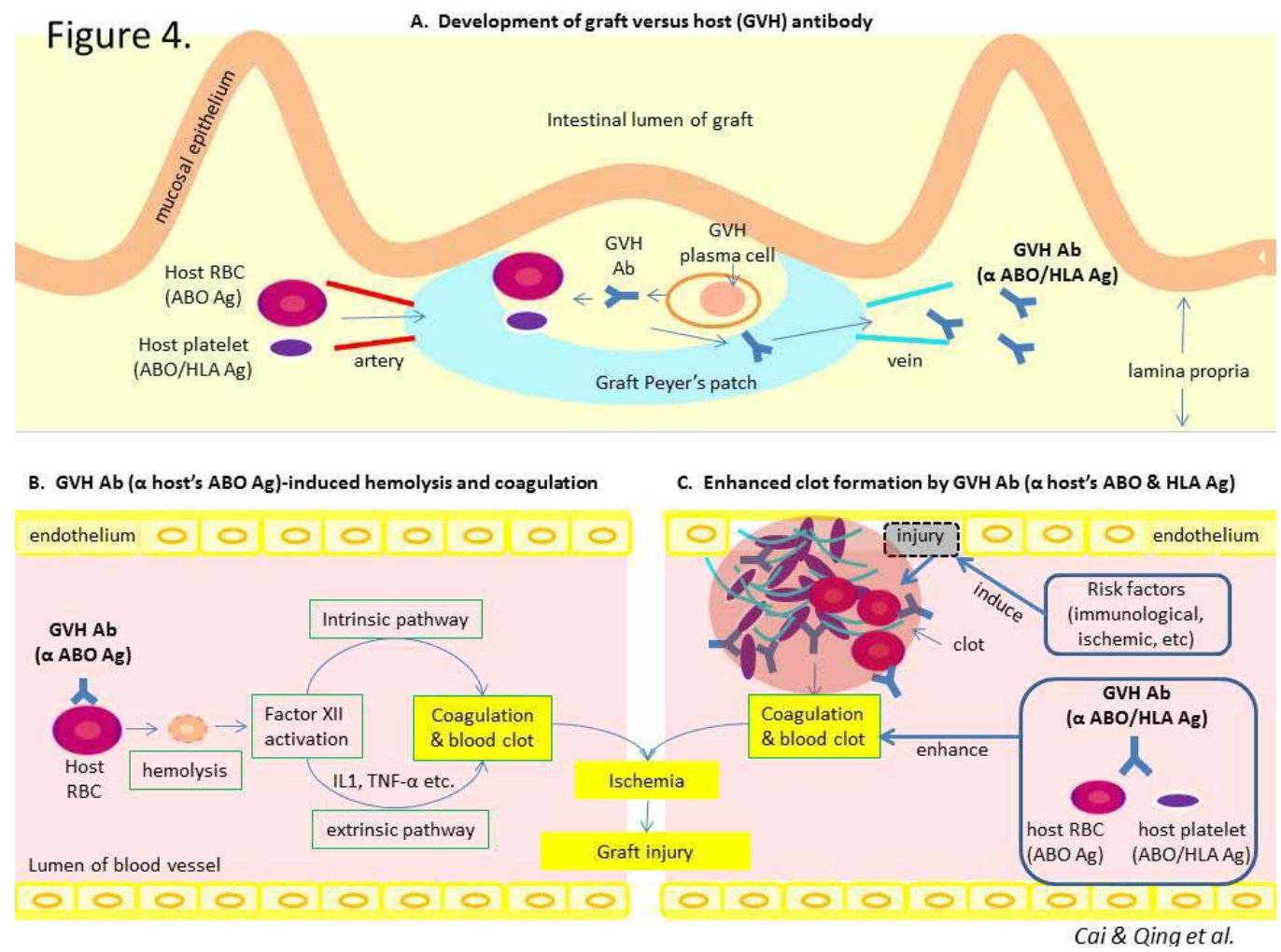

Figure 4: Development of graft versus host (GVH) antibody and its roles in allograft injury. A) Development of GVH antibody.

Peyer's patch is used as a representative intestinal lymphoid tissue. In ABO-compatible but unmatched transplantation, host RBC, platelet, and other cells with mismatched host's alloantigens (ABO, HLA etc.) on the surface may trigger GVH antibody responses in intestinal lymphoid tissues.

B) GVH antibody-induced hemolysis and coagulation. GVH antibodies against host RBC surface antigens bind and lyse host RBC-hemolysis, which activate coagulation and blood clot formation via both intrinsic and extrinsic pathways. Blood clot formation results in allograft ischemia and consequent tissue injury and dysfunction.

C) Enhanced clot formation by GVH antibodies. Primary endothelium injury of intestinal transplant might be induced by various risk factors which include patient's immune reaction against graft's antigens or by allograft ischemia and reperfusion. Endothelia injury activates coagulation and clot formation. GVH antibodies against both platelets and RBCs, the major components of a blood clot, further enhance the formation of the clot and deteriorate the ischemic injury of the allograft.

Citation: Cai J, Qing X, Wu G, Everly M, Cheng E, et al. (2015) Is ABO-Compatible but Non-Identical Intestinal Transplant Comparable to ABO-Identical Transplant? An Analysis of the UNOS Registry. SOJ Immunol 3(5): 1-9. DOI: DOI: http://dx.doi.org/10.15226/2372- 
In the diagnosis of allograft rejection in intestinal transplants, lymphoid activation is commonly found in the Peyer's patch (a closely aggregated nodule of lymphoid tissue in the wall of the small intestine) of the allograft [22]. However, activated lymphocytes in the graft Peyer's patch may be of either recipient or donor origin. Activated lymphocytes of recipient origin demonstrate an active host versus graft immunity; while if activated lymphocytes are of donor origin, GVH immune responses are indicated. Interestingly, in a rat small bowel transplant rejection model, donor lymphocytes became more activated than recipient lymphocytes in the graft mesenteric lymph node and Peyer's patches. The presence of more activated GVH immune responses suggests that GVH immunity may contribute to graft damage [23]. Unfortunately, from this registry database analysis, we could not determine whether the allograft rejection and consequent graft loss in the ABOcompatible transplant group are associated with GVH disease since information on patients' GVH disease and biopsy reports of cases of rejection is not available in the registry data.

We propose that in $\mathrm{ABO}$-compatible intestinal transplantation, GVH immune reactions against mismatched host blood type antigens may participate in the pathogenesis of transplant rejection through two potential mechanisms. Certainly, other mismatched host alloantigens, such as Human Leukocyte Antigens (HLA), may also trigger GVH immune responses.

The first potential mechanism of GVH immunity participating in allograft rejection involves intravascular hemolysis, which results from GVH immune responses against mismatched recipient blood type antigens. When an allograft from a blood type 0 donor is transplanted to a blood type A recipient (host), immune cells (e.g. GVH plasma cells) from the graft will mount immune responses (e.g. GVH antibodies) against surface antigens of host blood cells [ABO antigens on Red Blood Cells (RBCs) and platelets, and HLA antigens on platelets, etc.] (Figure 4A). These GVH antibodies produced by graft lymphoid tissues against host RBCs will cause intravascular hemolysis in $\mathrm{ABO}$-compatible transplant recipients (Figure 4B). Coagulation activity of hemolysis has been discovered and confirmed for decades [24-28]. The clinical consequence of coagulation depends on the severity of intravascular hemolysis. It has been reported that acute massive intravascular hemolysis may sometimes cause Disseminated Intravascular Coagulation (DIC), the most severe form of coagulation $[27,28]$. In ABO-compatible intestinal transplantation, the amount of anti-host RBC antibodies produced from GVH reactions might not be high enough to rapidly cause systemic symptoms like DIC as reported in transfusion reactions [29] and in a large dose IVIG treatment [28]. However, the effects of these GVH antibodies on induction of immune hemolysis, activation of platelet aggregation/coagulation, and formation of blood clots will certainly be harmful to the function of the allograft. The clinical manifestations of this GVH antibodyinduced hemolysis and consequent coagulation/clot formation may perfectly mimic allograft rejection caused by the host versus graft immunological reactions. However, it is still possible to distinguish the tissue injuries resulting from these two different causes since GVH antibody-induced hemolysis and consequent clot formation will affect not only the allograft itself, but also the patient's native tissues, while inflammatory changes of allograft rejection are only seen within the intestinal graft itself.

The second potential mechanism of GVH immunity participating in allograft rejection involves the enhanced platelet aggregation, coagulation, and clot formation in the vasculature of the intestinal allograft (Figure 4C). Primary endothelial injury of intestinal transplant may be initiated by a patient's immune reaction against the graft antigens or by allograft ischemia and reperfusion. Endothelial injury activates the coagulation cascade in which the recipient's platelet is the major player in forming a blood clot. The consequences of blood clot formation in the vasculature include ischemia and even infarction of graft tissues supplied by clotted vessels. The secondary tissue damage following primary endothelial injury will further deteriorate the allograft function, which finally results in graft failure [30]. In ABO-compatible intestinal transplantation (e.g. $\mathrm{O}$ donor to A recipient) with a large quantity of lymphoid tissue, the transplant may contain enough of the recipient's antigen-specific immune cells that will mount GVH immune responses against mismatched recipient's antigens. These antigens include not only ABO blood type antigens, but also HLA antigens, which are all expressed on the surface of platelets [18-21]. Either GVH HLA- or ABO-specific antibodies will bind to platelets or other blood cells of recipient origin at the site of activation of coagulation, which further enhances the formation of blood clots and results in graft failure.

Since this is a database analysis, findings and conclusions drawn from this study might be limited by the availability and integrity of variables of the database. Major limitations of this study include: 1) a high rate of missing observations for some variables; and 2) hypothesized mechanisms to be proven. Some variables show potential association with graft failure in univariate Cox analysis, such as donor Epstein-Barr virus sera status, patient hepatitis C virus sera status, patient hepatitis B virus surface antigens, patient cytomegalovirus immunoglobulin antibodies, patient liver dysfunction at transplantation, etc. However, there are $27-62 \%$ of patients with no information about these potential failure predictors. Therefore, they have to be excluded from multivariate Cox analysis to avoid selection bias. Exclusion of key variables from the analysis may affect the accuracy of the analysis. Even though we proposed potential mechanisms regarding how GVH reactions are involved in allograft injuries, there was no direct evidence from registry data to support these hypotheses. Further investigations are required to prove these hypotheses.

In conclusion, $\mathrm{ABO}$-compatible intestinal transplants were associated with a higher rate of acute rejection and a lower rate of long-term graft survival as compared to $\mathrm{ABO}$-identical transplants. We need to seriously reconsider the strategies to deal with ABO-compatible transplants. First, it is reasonable to avoid ABO-compatible transplantation when an identical donor is available. Certainly, this must be balanced against the potential risk of waiting for an $\mathrm{ABO}$-identical donor in the face of imminent death from liver failure. In addition, the patient's sensitization to HLA antigens needs to be considered, especially 
when donor specific antibodies are preexisting. Second, when ABOcompatible transplant is the only choice, the recipient deserves a more intense induction or maintenance immunosuppression to minimize the potential risk of GVH immune reactions. Third, monitoring patients for GVH immune reactions (GVH ABO or HLA antibodies, effector T-cells, et al), especially within the $1^{\text {st }}$ year post-transplant, may help to identify patients under risk of acute rejection and graft failure who need to be treated accordingly. Last, when RBC transfusion is needed for an ABO-compatible transplant recipient with detectable GVH antibodies, donor-type packed RBCs are recommended and should be washed to remove anti-recipient antibodies. In contrast, plasma should be of recipient's ABO type. Since a recipient type RBC transfusion will increase the target cells of GVH antibodies and a donor type plasma transfusion will increase the effectors-GVH antibodies, both will further intensify the GVH reaction-induced graft injury.

\section{Funding Source}

Terasaki Foundation

\section{References}

1. Jawitz OK, N GJ, Yuh DD, Bonde P. Impact of ABO compatibility on outcomes after heart transplantation in a national cohort during the past decade. J Thoracic Cardiovasc Surg. 2013;146:1239-45; discussion 45-6. doi: 10.1016/j.jtcvs.2013.06.040.

2. Sjogren J, Ljungdahl-Waller F, Senneby E, Ekmehag B, Koul B, Nilsson J. Heart transplantation with $\mathrm{ABO}$-identical versus $\mathrm{ABO}$-compatible cardiac grafts: influence on long-term survival. Scand Cardiovasc J. 2010;44:373-379. doi: 10.3109/14017431.2010.509450.

3. Taghavi S, Jayarajan SN, Furuya Y, Komaroff E, Shiose A, Leotta E, et al. Single-lung transplantation with $\mathrm{ABO}$-compatible donors results in excellent outcomes. J Heart Lung Transplant. 2014;33(8):822-828. doi: 10.1016/j.healun.2014.04.006.

4. Taghavi S, Jayarajan SN, Furuya Y, Komaroff E, Shiose A, Leotta E, et al. Examining $\mathrm{ABO}$ compatible donors in double lung transplants during the era of lung allocation score. Ann Thorac Surg. 2014;98(4):11671174. doi: 10.1016/j.athoracsur.2014.05.037.

5. Aladag M, Gurakar A, Camci C, Yong Y, Wright H, Nour B, et al. Compatible $\mathrm{ABO}$ mismatch and liver transplantation: a single center's experience. Exp Clin Transplant. 2006;4(1):467-469.

6. Koukoutsis I, Bellagamba R, Tamijmarane A, Gunson B, Muralidharan $\mathrm{V}$, Wigmore SJ, et al. Outcomes after identical and compatible orthotopic liver transplantation for fulminant hepatic failure: a single center experience in UK. Transplant Int. 2007;20(8):659-665.

7. Bjoro K, Ericzon BG, Kirkegaard P, Höckerstedt K, Söderdahl G, Olausson M, et al. Highly urgent liver transplantation: possible impact of donor-recipient $\mathrm{ABO}$ matching on the outcome after transplantation. Transplantation. 2003;75(3):347-53.

8. Cai J, Wu G, Qing A, Edwards EB, Harper AM, Snyderf JJ, et al. OPTN/ SRTR 2014 Data Report: intestine. Clin Transpl, 2014; Suppl 1:97-111. doi: 10.1111/ajt.12582.

9. Calhoun B, Pothiawala M, Musa G, Baron B. Indicators of clinically significant red cell antibodies produced by sensitized lymphocytes in liver transplant patients. Immunohematology. 1991;7(2):37-3 9.

10. Ramsey G. Red cell antibodies arising from solid organ transplants. Transfusion. 1991;31(1):76-86.
11. Ramsey G, Nusbacher J, Starzl TE, Lindsay GD. Isohemagglutinins of graft origin after $\mathrm{ABO}-$ unmatched liver transplantation. New Eng J Med. 1984;311(18):1167-1170.

12.Triulzi DJ, Shirey RS, Ness PM, Klein AS. Immunohematologic complications of ABO-unmatched liver transplants. Transfusion. 1992;32(9):829-833.

13. Ramsey G, Sherman LA. Transfusion therapy in solid organ transplantation. Hematol Oncol Clin North Am. 1994;8(6):11171129.

14. Bakr MA, Abbas TM, Mustafa A, Ghoneim MA. Hemolytic anemia after $\mathrm{ABO}$ nonidentical living donor kidney transplantation. Clin Exp Nephrol. 2009;13(2):161-5.

15. Salminen S, Bouley C, Boutron-Ruault MC, Cummings JH, Franck A, Gibson GR, et al. Functional food science and gastrointestinal physiology and function. Br J Nutr. 1998;80 Suppl 1:S147-171.

16. Taylor AL, Gibbs P, Bradley JA. Acute graft versus host disease following liver transplantation: the enemy within. Am J Transplant. 2004;4(4):466-474.

17. Mazariegos GV, Abu-Elmagd K, Jaffe R, Bond G, Sindhi R, Martin L, et al. Graft versus host disease in intestinal transplantation. Am J Transplant. 2004;4(9):1459-1465.

18.Wu G, Selvaggi G, Nishida S, Moon J, Island E, Ruiz P et al. Graft-versus-host disease after intestinal and multivisceral transplantation. Transplantation 2011;91(2):219-224. doi: 10.1097/TP.0b013e3181ff86ec.

19. Smith DM, Agura E, Netto G, Collins R, Levy M, Goldstein R, et al. Liver transplant-associated graft-versus-host disease. Transplantation. 2003;75(1):118-126.

20. Assi MA, Pulido JS, Peters SG, McCannel CA, Razonable RR. Graft-vs.host disease in lung and other solid organ transplant recipients. Clin Transplant. 2007;21(1):1-6.

21. Grant D, Zhong R, Gunn H, Duff J, Garcia B, Keown P, et al. Graftversus-host disease associated with intestinal transplantation in the rat. Host immune function and general histology. Transplantation. 1989;48(4):545-549.

22. Yildiz BD. Where are we at with short bowel syndrome and small bowel transplant. World J Transplant. 2012;2(6):95-103. doi: 10.5500/wjt.v2.i6.95.

23. Webster GA, Wood RF, Pockley AG. Identification of localized antihost responses in the graft mesenteric lymph node and Peyer's patches after rat small bowel transplantation. Immunol Invest. 1997;26(5-7):517-529

24. Crosby WH, Dameshek W. Paroxysmal nocturnal hemoglobinuria; the mechanism of hemolysis and its relation to the coagulation mechanism. Blood. 1950;5(9):822-842.

25. Walther G. Coagulation activity of hemolysis. Bibl Haematol. 1957;6:176-9; discussion 80-2.

26. Riedler G, Frick PG, Straub PW. The effects of acute intravascular hemolysis on coagulation and fibrinolysis. Helv Med Acta. 1968;34(3):205-216.

27. Atichartakarn V, Jootar S, Pathepchotiwong K, Srichaikul T. Acute massive intravascular hemolysis and disseminated intravascular coagulation. Southeast Asian J Trop Med Public Health. 1979;10(3):338-341.

28. Comenzo RL, Malachowski ME, Meissner HC, Fulton DR, Berkman EM. 
Immune hemolysis, disseminated intravascular coagulation, and serum sickness after large doses of immune globulin given intravenously for Kawasaki disease. J Pediatr. 1992;120(6):926-928.

29. Strobel E. Hemolytic Transfusion Reactions. TransfusMed Hemother.
2008;35:346-353. doi: 10.1159/000154811.

30. Cai J, Terasaki PI. Humoral theory of transplantation: mechanism, prevention, and treatment. Hum Immunol 2005;66(4):334-342. 